\title{
El discurso del tuit: un análisis lingüístico, sociodiscursivo y sociopragmático*
}

\author{
LUZ ELENA ARRIETA BETTÍN** \\ GLORIA SMITH AVENDAÑO DE BARÓN ${ }^{* * *}$
}

Recepción: 8 de noviembre de 2017

Aprobación: 5 de febrero de 2018

Forma de citar este artículo: Arrieta, L. E. \& Avendaño G. S. (2018). El discurso del tuit: un análisis lingüístico, sociodiscursivo y sociopragmático. Cuadernos de Lingüística Hispánica, (32), 107-130.

* Artículo de investigación del Grupo de Investigación para los Estudios Sociolingüísticos del Caribe e Hispanoamérica".

** Magíster en Lingüística, docente de la Institución Educativa "Técnico Agroindustrial Lisandro Cely" de Mongua, Boyacá. Correo electrónico: lucyarrieta2@hotmail.com

*** Doctora en Filología Española, magíster en Lingüística Hispánica y especialista en Literatura y Semiótica. Integrante del Grupo de Investigación para el Estudio Sociolingüístico del Caribe e Hispanoamérica (GIESCAH) y docente de la Escuela de Idiomas de la Universidad Pedagógica y Tecnológica de Colombia. Correo electrónico: gloriaesmid@gmail.com 


\title{
Resumen
}

El objetivo de este artículo fue caracterizar y analizar, desde perspectivas lingüísticas, sociodiscursivas y sociopragmáticas, los mensajes de Twitter enviados por el expresidente de Colombia Álvaro Uribe Vélez al presidente Juan Manuel Santos y su equipo de Gobierno (2010-2015), a fin de evidenciar los modos como el enunciador reproduce y legitima mecanismos de poder para influir en la opinión pública. La investigación se apoyó en la metodología del análisis crítico del discurso (ACD), paradigma interpretativo con enfoque cualitativo. Los resultados revelaron que los mensajes de Twitter de Uribe contienen un lenguaje cargado de marcas deícticas personales, espaciales y temporales, de implicaturas conversacionales particularizadas y de estrategias discursivas, que conllevan intencionalidades encaminadas a denunciar y censurar decisiones y actuaciones administrativas y políticas del presidente Santos. El enunciador, Uribe, autentifica sus principios político-ideológicos y sus acciones pasadas y presentes a costa de la deslegitimación de su sucesor y el grupo de colaboradores, pues el propósito es mostrar que su Gobierno fue mejor y que aún ejerce el poder para inmiscuirse crítica y públicamente en los asuntos políticos, sociales y económicos de la vida nacional y, a su vez, incidir y ganar aceptación de los lectores y de la opinión pública en general.

Palabras clave: Twitter, poder, perspectiva lingüística, sociodiscursiva y sociopragmática.

\section{The Speech of the Twetter: A Linguistic, Sociodiscursive and Sociopragmatic Analysis}

\begin{abstract}
This paper is aimed to characterize and analyze, from linguistic, sociodiscursive and sociopragmatic perspectives, the Twitter messages sent by former Colombian President Álvaro Uribe Vélez to President Juan Manuel Santos and his Government team (2010-2015), in order to demonstrate the ways in which the enunciator reproduces and legitimates mechanisms of power to influence public opinion. The research was based on the methodology of critical discourse analysis (CDA), an interpretive paradigm with a qualitative approach. The results revealed that Uribe's Twitter messages contain a language loaded with personal, spatial and temporal deictic marks, with particularized conversational implications and discursive strategies, which carry intentions aimed at denouncing and censuring President Santos' administrative and political decisions and actions. The enunciator, Uribe, authenticates his politico-ideological principles and his past and present actions at the expense of the de-legitimization of his successor and the group of collaborators, since the
\end{abstract}


purpose is to show that his Government was better and still exercises the power to interfere with criticism and publicly in the political, social and economic affairs of national life and, in turn, influence and gain acceptance of readers and public opinion in general.

Keywords: Twitter, power, linguistic, sociodiscursive and sociopragmatic perspectives.

\section{Le discours du tweet : une analyse linguistique, Socio-discursif et socio- pragmatique}

\section{Résumé}

L'objectif de cet article a été celui de caractériser et analyser, à partir de perspectives linguistiques, socio-discursives et socio-pragmatiques, les messages Twitter envoyés par Álvaro Uribe-Vélez, ancien président de la Colombie, et par le président Juan-Manuel Santos et son équipe de gouvernement (2010-2015), afin de mettre en évidence les modes comment l'énonciateur reproduit et légitime des mécanismes de pouvoir pour influencer l'opinion publique. La recherche s'est appuyée sur la méthodologie de l'analyse critique du discours (ACD), paradigme interprétatif avec une approche qualitative. Les résultats ont révélé que les messages de Twitter d'Uribe contiennent un langage chargé de marques déictiques personnelles, spéciales et temporelles, d'implicatures conversationnelles particularisées et de stratégies discursives, qui entrainent des intentionnalités qui visent à dénoncer et à censurer des décisions et des procédures administratives et politiques du président Santos. Lénonciateur, Uribe, authentifie ses principes politique-idéologiques et ses actions passées et présente au détriment de la délégitimation de son successeur et le groupe de collaborateurs, car le but est celui de montrer que son gouvernement a été meilleur et qu'il exerce encore le pouvoir de s'immiscer critique et publiquement dans les affaires politiques, sociales et économiques de la vie nationale et, à leur tour, influer et gagner de l'acceptation des lecteurs et de l'opinion publique en général.

Mots clés: Twitter, pouvoir, perspective linguistique, socio-discursive et socio-pragmatique.

\section{o Discurso do Tuit: uma análise línguistico, sociodiscursivo e sociopragmático}

\section{Resumo}

0 objetivo deste artigo foi caracterizar e analisar, a partir de perspectivas lingüísticas, sociodiscursivas e sociopragmáticas, as mensagens do Twitter enviadas pelo ex-presidente colombiano Álvaro Uribe Vélez ao presidente Juan Manuel Santos e sua equipe do governo (2010-2015), a fim de demonstrar as maneiras pelas quais o enunciador reproduz e le- 
gitima mecanismos de poder para influenciar a opinião pública. A pesquisa baseou-se na metodologia da análise crítica do discurso (ACD), um paradigma interpretativo com abordagem qualitativa. Os resultados revelaram que as mensagens do Twitter de Uribe contêm uma linguagem carregada de marcas deítticas pessoais, espaciais e temporais, com implicações conversacionais e estratégias discursivas particulares, que carregam intenções de denunciar e censurar as decisões e ações administrativas e políticas do presidente Santos. 0 enunciador, Uribe, autentica seus princípios político-ideológicos e suas ações passadas e presentes em detrimento da deslegitimação de seu sucessor e do grupo de colaboradores, pois o objetivo é mostrar que seu governo era melhor e ainda exerce o poder de interferir nas críticas e publicamente nos assuntos políticos, sociais e econômicos da vida nacional e, também, influenciar e ganhar aceitação dos leitores e da opinião pública em geral.

Palavras-chave: Twitter, poder, perspectiva lingüística, sociodiscursivo e sociopragmático. 


\section{Introducción}

Actualmente, las redes sociales tienen gran auge, gracias a sus variados modos de expresar y comunicar que aportan a la significación, la discusión y la divulgación de ideas, sentimientos y posturas políticas. Los mensajes de Twitter proponen un nuevo sistema de interacción comunicativa, pues, al contrario de otras redes sociales, esta requiere síntesis, claridad y puntualidad en la redacción del texto. Los trinos han tomado una fuerza inusitada y masificada: la economía del lenguaje y los escasos estudios lingüísticos existentes en torno de esta temática constituyen una situación divergente, en la medida en que transforman una modalidad de comunicación, de expresión global, en un proceso comunicativo interactivo e inmediato (Van Dijk, 1995). La importancia de este tipo de discurso radica en la intención comunicativa, basada en la producción y articulación de un performance, es decir, una puesta en escena atravesada por unas razones, entre otras: informar, denunciar, criticar, agredir, convencer y persuadir.

Las nuevas aplicaciones y redes sociales, que proponen estrategias cada vez más sencillas para lograr un contacto mucho más efectivo, eficiente, inmediato y óptimo entre personas de distintos géneros, ideologías, culturas, razas y creencias, confirman un nivel de crecimiento en masa. Su uso y las situaciones culturales que estas producen, conllevan nuevos planteamientos en los modelos lingüísticos, cambios en la forma de procesar información y de recibirla, entre otros.

El objetivo principal de la presente investigación fue caracterizar y analizar, desde una mirada lingüística, sociodiscursiva y sociopragmática, el contenido de los mensajes de Twitter enviados por el expresidente de Colombia Álvaro Uribe Vélez al presidente Juan Manuel Santos y su equipo de Gobierno, en los dos períodos presidenciales, 2010-2015, con el fin de interpretar y explicar el sentido que subyace al uso de marcas deícticas personales, temporales y espaciales, y de estrategias discursivas de legitimación, deslegitimación, persuasión, acusación y justificación, y así evidenciar los modos como el enunciador reproduce y legitima mecanismos de poder para influir en la opinión pública. Para tal fin se siguió la metodología propuesta y desarrollada por estudiosos del análisis crítico del discurso (ACD), (Van Dijk, 2009; Pardo, 2013, entre otros).

Es relevante analizar los modos distintos en los que se produce el discurso en cualquier evento 0 acción comunicativa, en un contexto en el que los medios de comunicación y las nuevas tecnologías han adquirido especial preponderancia. Por lo tanto, es oportuno conocer y examinar cómo el fenómeno de las redes sociales ha promovido un tipo de intercambio comunicativo ágil y cargado de sentido. En el análisis del discurso contemporáneo se puede observar que las maneras en que los usuarios se relacionan 
están determinadas, entre otras razones, por las limitaciones y los alcances que impone el contexto de la virtualidad, porque las nuevas tecnologías facilitan el diálogo constante, en la medida en que existe una proximidad comunicativa y una sensación de copresencia que los usuarios manifiestan en el momento de vincularse con otros (Pano \& Mancera, 2014). Sin duda, la virtualidad, metódica y sistemáticamente, ha irrumpido en la vida cotidiana de los seres humanos; la explosión de los escenarios mediáticos, posmediáticos y virtuales son acogidos por el sistema de las redes sociales, sin que medie, por ejemplo, un análisis desde perspectivas lingüísticas, sociodiscursivas y sociopragmáticas para descubrir cómo a través del discurso que circula en las redes sociales se configuran mecanismos de poder.

\section{Metodología}

Como ya se mencionó, la presente investigación se apoyó en las perspectivas metodológicas del ACD. Van Dijk (2009), su pionero, enfatiza el papel fundamental del discurso en la reproducción del poder (especialmente en el abuso) y la dominación en la sociedad. En este contexto, ha investigado acerca de las formas complejas como los medios masivos de comunicación y los dirigentes políticos controlan el acceso al discurso público y, desde luego, la ideología y las creencias de sus receptores manipulan la información e inciden en la percepción de los acontecimientos, especialmente, sociales, políticos y económicos de una nación, o de una colectividad, con el propósito de convencer, persuadir, ganar adeptos y orientar la toma de decisiones hacia sus propios intereses.

Para esta investigación, el corpus se conformó con 27 tuits enviados por el expresidente Álvaro Uribe Vélez al presidente de Colombia, Juan Manuel Santos y su equipo de Gobierno, durante los años 2010 a 2015. Se eligieron esos mensajes por ser los que más contenían marcas deícticas personales, espaciales y temporales, implicaturas particularizadas y estrategias discursivas de legitimación y deslegitimación. Para abordar el análisis del discurso en los tuits, se adoptaron los planteamientos de Pardo (2013), quien propone las siguientes fases: a) exploratoria descriptiva, que consiste en la caracterización de las unidades de análisis, establecimiento de categorías; b) analítica, basada en el análisis lingüístico que va de la sintaxis a la semántica y a la pragmática, para dar cuenta de fenómenos sociopolíticos, socioculturales y sociodiscursivos presentes en los discursos que circulan públicamente en una comunidad; c) interpretativa, que resulta del análisis cualitativo sustentado en la producción de sentido del texto.

Concretamente, el procedimiento metodológico seguido en la presente investigación fue el siguiente: (i) selección del corpus. La recolección de datos se realizó a través de Internet, en la página web de la red social www.twitter.com. Se ingresó a la cuenta oficial de Twitter del expresidente Álvaro Uribe Vélez, se leyeron los trinos del año 2010 hasta el 2015 y se eligieron los que se consideraron pertinentes al propósito de la investigación. (ii) Determinación de categorías en 
el contexto de los tres niveles de análisis del corpus. En el lingüístico: se describieron los tres tipos de deícticos -personales, temporales y espaciales- y se interpretó el sentido que subyace en su uso. En el sociodiscursivo, se describieron las estrategias discursivas de legitimación, deslegitimación, persuasión, acusación y justificación, y se interpretaron para mostrar cómo el enunciador protege su imagen y descalifica la del enunciatario. En el sociopragmático, se desentrañaron y explicaron las implicaturas que contienen algunos tuits. Como ya se anotó, se abordaron estos tres tipos de análisis para develar cómo el enunciador reproduce y legitima su poder ante la opinión pública, para influir en los modos de percibir la realidad del país, de sentir, de pensar, y en la toma de decisiones políticas de los colombianos.

\section{Resultados: análisis y discusión}

En este apartado se expone el estudio lingüístico, el sociodiscursivo y el sociopragmático solo de una muestra del corpus ${ }^{1}$ :

\subsection{Perspectiva lingüística}

Como es bien sabido, la lingüística da cuenta de los fenómenos propios de una lengua, de su estructura, pero también de su uso en contextos reales de comunicación a través de distintos medios. En este trabajo se estudian los deícticos presentes en los mensajes de Twitter ya aludidos.

\section{Deícticos}

Según Noguera (2010), la enunciación se organiza a través de un sistema de referencias fundado en las categorías de persona (el yo), de tiempo (el ahora) y de espacio (el aquî), y a partir de estas tres categorías se conforma la deixis del enunciado. Este vocablo se deriva del griego y significa "indicar" o "mostrar"; así que la deixis está constituida por las marcas lingüísticas que, desde el enunciado, señalan el acto de enunciación; dicho de otra manera, por las palabras que remiten a los participantes y a las circunstancias propias de una determinada situación enunciativa. La teoría de la enunciación establece que los actos de habla tienen lugar a través de los enunciados y es en el momento de su puesta en escena que esta alcanza su mayor relevancia, por lo tanto, se encarga de estudiar la relación entre el enunciado y su contexto, y, por ende, su comprensión. El concepto de deixis alude a "la localización de personas, objetos, procesos, acontecimientos y actividades de las que se habla en relación con el contexto espacio temporal creado y mantenido por el acto de enunciación" (Lyons, 1980, p. 261). Los deícticos se refieren a la función

1 Por limitación de espacio, en este artículo no se presenta el análisis de todos los 27 mensajes. 
de los pronombres personales y demostrativos, de los tiempos gramaticales y los términos lexicales que marcan las coordenadas espaciotemporales del acto de la enunciación. Para Jakobson (1957), los shifters, deícticos o conmutadores, son símbolos-índices que remiten al mensaje e implican una referencia al proceso de enunciación. Vale aclarar que las marcas lingüísticas (pronombres, adverbios, desinencias verbales, etc.) constituyen deixis siempre que estén en relación con el sujeto de la enunciación.

Deícticos de persona. Se expresan a través de pronombres personales, posesivos y demostrativos. Son deícticos personales, los siguientes: el pronombre de primera persona del singular (yo) y del plural (nosotros); los de segunda, singular y plural respectivamente (tú, usted, ustedes, vosotros); los de tercera singular y plural (él, ella, ellos, ellas) y los átonos (me, nos, te, le, les, lo, los, entre otros). También se consideran deícticos de esta índole las desinencias verbales que indican las respectivas personas; ejemplos: "vote", "cree", "éramos". Son posesivos: mi, mío, mía, tu, tuyo, tuya, su, suyo, suya, y demostrativos: este, esto, estos, esta, estas, aquello, aquella, aquellos, aquellas, eso, esos, etc.

Deícticos de tiempo. Atañen a los adverbios de tiempo, como ayer, hoy, mañana, pasado mañana, etc. También constituyen deixis los tiempos verbales, la desinencia temporal del verbo conjugado.

Deícticos de espacio. Se manifiestan en adverbios de lugar, como allí, aquí, allá, más cerca, etc. También son deícticos espaciales los pronombres demostrativos y los verbos cuya acción sugiere espacialidad, como "ir", "venir", "entrar", "salir", entre otros. Se debe tener en cuenta que cuando los demostrativos cumplen la función gramatical de ser referencia anafórica de un concepto mencionado con anterioridad, no constituyen deixis.

En este análisis lingüístico se muestra la relación contractual que el enunciador posee con el enunciatario. Se alude aquí a lo expuesto por Verón (1985), quien sostiene que el contrato de lectura no reside solamente en los contenidos, sino que se encuentra fundamentalmente en los contenidos que son tomados a cargo por una estructura enunciativa donde alguien (el enunciador) habla y desde donde se le propone un lugar al que escucha o lee (el enunciatario). En este caso, el expresidente Álvaro Uribe Vélez asume el rol de enunciador, y Juan Manuel Santos, el equipo de Gobierno, los seguidores de Uribe y lectores en general, el de enunciatarios.

Se elaboró la siguiente tabla en la que se presenta de modo textual cada tuit, se registran los deícticos recurrentes, la palabra que los representa (ejemplo) y el sentido que se le atribuye a cada uno según la situación de comunicación y el contexto social y político 
de Colombia en el momento en que fueron emitidos (por limitación de espacio, en este artículo presentamos el análisis solo de los mensajes: 1, 9, 12, 16, 20, 22 y 24):

Tabla 1. Tuit $1 *$

* “A muchos nos duele la violencia, otros la aprovechan para su ascenso político. Ni las tenta-
ciones cómodas de retiro ni la ofensa diaria nos apartarán de la batalla alegre y firme de todas
las horas". (15 abr. 2011)

\begin{tabular}{|l|l|l|}
\hline \multicolumn{1}{|c|}{ Deícticos } & \multicolumn{1}{|c|}{ Ejemplo } & \multicolumn{1}{c|}{ Sentido } \\
\hline $\begin{array}{l}\text { Pronombre (deíctico de } \\
\text { persona) }\end{array}$ & $\begin{array}{l}\text { Nos (indirecto o } \\
\text { átono) }\end{array}$ & $\begin{array}{l}\text { Mediante el empleo de este pronombre, Uribe, en su con- } \\
\text { dición de expresidente, alza la voz para hablar en nombre } \\
\text { de un conglomerado de colombianos, para indicar que él } \\
\text { siente la misma indignación y repudio ante la inseguridad } \\
\text { del país, con ello intenta tocar las fibras sensibles de los } \\
\text { lectores y ganar su adhesión. }\end{array}$ \\
\hline $\begin{array}{l}\text { Desinencias verbales } \\
\text { (deíctico de tiempo) }\end{array}$ & $\begin{array}{l}\text { Duele } \\
\text { Aprovechan }\end{array}$ & $\begin{array}{l}\text { Verbos conjugados en tiempo presente para significar su } \\
\text { enojo frente a la antítesis muerte-oportunismo, que se- } \\
\text { gún el enunciador, cabalga en el Palacio de Nariño (cuyo } \\
\text { "huésped" es el presidente Santos), pero advierte que no } \\
\text { guardará silencio ante tal despropósito, pues se siente con } \\
\text { el poder suficiente para denunciar ante la opinión pública. }\end{array}$ \\
\hline
\end{tabular}

Generalmente, los deícticos de persona son los pronombres personales e, indirectamente, algunos posesivos y demostrativos de primera y segunda persona de singular 0 plural. Con la expresión "nos duele", el enunciador (Uribe) insinúa que él es un colombiano más, preocupado por lo que le pueda suceder a sus compatriotas en manos del Gobierno de Santos; utiliza un deíctico personal, pronombre indirecto o átono, "nos", para interpretar el sentimiento de un pueblo y alzar su voz de rechazo a la violencia que aún campea en la nación. Se involucra con el otro, muestra solidaridad y cercanía con el pueblo, toca susceptibilidades de los lectores para indicar que Santos maneja inadecuadamente el conflicto con la guerrilla de las FARC; de este modo, intenta crear conciencia en la opinión pública del rumbo equivocado que toma el país; con el uso de la primera persona configura y transmite una autoimagen de "salvador" (Arrieta, 2013). 
Tabla 2. Tuit 9*

* "El Gobierno Santos comunica a mandos militares que busca negociar con el terrorismo a través de la dictadura Chávez, desmotiva a nuestros soldados... En nuestro Gobierno sufrimos terrorismo pero nunca los cálculos nos llevaron a debilitar la política”. (18 oct. 2012)

\begin{tabular}{|l|l|l|}
\hline \multicolumn{1}{|c|}{ Deícticos } & \multicolumn{1}{|c|}{ Ejemplo } & \multicolumn{1}{c|}{ Sentido } \\
\hline $\begin{array}{l}\text { Pronombre po- } \\
\text { sesivo } \\
\text { (deíctico de per- } \\
\text { sona) }\end{array}$ & Nuestros & $\begin{array}{l}\text { Con este deíctico posesivo, que hace parte de la expresión "Nues- } \\
\text { tros soldados", el enunciador deja entrever una actitud afectiva } \\
\end{array}$ \\
& & $\begin{array}{l}\text { y protectora hacia ellos, manifiesta preocupación por su bienes- } \\
\text { tar. Se infiere también una actitud de cercanía con sus lectores y } \\
\text { seguidores, los implica en un sentimiento de aprecio, respeto y } \\
\text { defensa de quienes arriesgan su vida por defender la patria. }\end{array}$ \\
\hline
\end{tabular}

Aquí, el enunciador le recrimina al enunciatario el desestímulo, el abandono y la desprotección de los militares, quienes han luchado siempre en contra de toda forma de terrorismo que atente contra la seguridad del país. Con este tuit, ataca la imagen de Santos, repudia la abolición de la que fuera su política orientada a mantener la seguridad democrática, les recuerda a los enunciatarios los aciertos de su Gobierno y delata las equivocaciones del presidente en ejercicio. Este trino se convierte en un lamento de lo que fue la seguridad del país en contraste con lo que es ahora.

Tabla 3. Tuit $12 *$

*"Todo lo contrario de aquello que se decía como ministro de Defensa y candidato".

(20 mayo 2012)

\begin{tabular}{|l|l|l|}
\hline \multicolumn{1}{|c|}{ Deícticos } & \multicolumn{1}{|c|}{ Ejemplo } & \multicolumn{1}{c|}{ Sentido } \\
\hline $\begin{array}{l}\text { Pronombre } \\
\text { demostrativo } \\
\text { (deíctico de- }\end{array}$ & Aquello & $\begin{array}{l}\text { Con este deíctico demostrativo, "aquello", se refiere a los discursos } \\
\text { pronunciados por Santos antes de ser presidente. Aquí se denuncia } \\
\text { mostrativo) }\end{array}$ \\
& & una incongruencia, un cambio repentino entre el decir y el proceder. \\
\hline
\end{tabular}

El enunciador delata ante la opinión pública la contradicción evidente en las decisiones trascendentales de quien está gobernando el país; implícitamente Uribe advierte el peligro que ello reviste en la vida de los colombianos. 
Tabla 4. Tuit 16*

*"Sorpresas: antes fuimos útiles en TLC con USA, ahora lo hizo la habilidad del Gbno (sic) actual”. (12 abril 2012)

\begin{tabular}{|l|l|l|}
\hline Deícticos & Ejemplo & \multicolumn{1}{c|}{ Sentido } \\
\hline $\begin{array}{l}\text { Adverbios } \\
\text { (deícticos tempo- } \\
\text { rales) }\end{array}$ & Antes, ahora & $\begin{array}{l}\text { Mediante el deíctico temporal "antes", Uribe, de modo irónico, } \\
\text { censura la desfachatez del Gobierno de Santos al autoendilgarse el } \\
\text { logro de la firma del TLC con Estados Unidos, desconociendo por } \\
\text { completo las gestiones realizadas por el Gobierno de su antecesor. } \\
\text { Una vez más pone en evidencia las acciones desconsideradas y } \\
\text { poco éticas del presidente en ejercicio. }\end{array}$ \\
\hline
\end{tabular}

Hay un mensaje implícito en las palabras irónicas "sorpresas", "antes" y "ahora", pues de ellas se infiere la animosidad y la molestia de Uribe por una injusticia de la que ha sido víctima: la negación de un logro también suyo; con este tuit se denuncia la deshonestidad de Santos al proclamar un mérito que no le corresponde.

Tabla 5. Tuit 20*

*"Pte (sic) Santos miente, jamás le recomendé un ministro". (9 febr. 2013)

\begin{tabular}{|c|c|c|}
\hline Deícticos & Ejemplo & Sentido \\
\hline $\begin{array}{l}\text { Adverbio de tiempo } \\
\text { (deíctico temporal) } \\
\text { Pronombre perso- } \\
\text { nal átono } \\
\text { (deíctico de per- } \\
\text { sona) } \\
\text { y desinencias } \\
\text { verbales } \\
\text { (deíctico temporal) }\end{array}$ & $\begin{array}{l}\text { Jamás } \\
\text { Le } \\
\text { recomendé, } \\
\text { miente }\end{array}$ & $\begin{array}{l}\text { El enunciador es contundente al responder una acusación que afecta } \\
\text { su imagen; por ello, usa el deíctico adverbial temporal "jamás", para } \\
\text { negar una acción abominable: la petición de puestos burocráticos en } \\
\text { el Gobierno de Santos. Con esta reacción discursiva, Uribe defiende } \\
\text { su comportamiento y, desde luego, su nombre, pues la intención es } \\
\text { evitar que su imagen de expresidente honorable, ético y poderoso se } \\
\text { derrumbe. } \\
\text { Este pronombre "le" reemplaza a la persona del presidente, a quien } \\
\text { se refiere Uribe para objetar el argumento que esgrime para explicar } \\
\text { el motivo del inconformismo y el distanciamiento entre los dos. }\end{array}$ \\
\hline
\end{tabular}

Uribe descalifica al presidente para refutar la acusación de la que es objeto. Se observa en este mensaje el coraje y el poder del enunciador para confrontar al mandatario y tildarlo de mentiroso; así pretende justificarse y defenderse ante sus lectores. 
Tabla 6. Tuit $22 *$

*"Señor presidente Santos, la traición a la Patria es uno de los delitos en que está incurriendo su Gobierno porque permite que asesine a los soldados y a policías y le da impunidad. Eso es traición a la patria”. (9 abr. 2013)

\begin{tabular}{|l|l|l|}
\hline Deícticos & Ejemplo & \multicolumn{1}{|c|}{ Sentido } \\
\hline $\begin{array}{l}\text { Pronombre } \\
\text { posesivo } \\
\text { (deíctico de } \\
\text { persona) }\end{array}$ & $\underline{\text { Su Gobierno }}$ & $\begin{array}{l}\text { Con el deíctico "su”, el enunciador se refiere al presidente } \\
\text { Santos y equipo de Gobierno, a quienes les recrimina la no } \\
\text { condena de la violencia propinada por la insurgencia a las } \\
\text { fuerzas armadas del país. }\end{array}$ \\
\hline $\begin{array}{l}\text { Desinencias } \\
\text { verbales } \\
\text { (deícticos } \\
\text { temporales) }\end{array}$ & $\begin{array}{l}\text { Es, incurriendo, } \\
\text { permite, asesine, } \\
\text { da }\end{array}$ & $\begin{array}{l}\text { Mediante estos verbos, que configuran deícticos de tiempo, se } \\
\text { culpa al Gobierno de Santos de encubrir crímenes contra las } \\
\text { fuerzas armadas del país, lo que, a juicio del enunciador, se } \\
\text { convierte en un delito. }\end{array}$ \\
\hline
\end{tabular}

Llama la atención el vocativo "Señor presidente Santos", con el que el enunciador le recuerda a su enunciatario que cohonestar los asesinatos perpetrados por los grupos guerrilleros se tipifica como una falta grave que puede ser penalizada. Este tuit revela el poder de Uribe, su carácter fuerte, contundente y frentero para acusar directamente a un jefe de Estado y expresar también el sentimiento de sus seguidores y lectores. Así intenta ganar simpatía, respeto y adhesión de la opinión pública.

Tabla 7. Tuit 24*

*"Lloro por mis compañeros asesinados, por el desengaño de saber que el presidente Santos prohibió el bombardeo a los señores de las Farc (sic) permitieron que los masacraran vilmente, porque para él somos simplemente unos desechables”. (20 abr. 2015)

\begin{tabular}{|l|l|l|}
\hline Deícticos & Ejemplo & \multicolumn{1}{c|}{ Sentido } \\
\hline $\begin{array}{l}\text { De sin en cia a } \\
\text { verbal } \\
\text { (deíctico } \\
\text { temporal) }\end{array}$ & $\begin{array}{l}\text { Lloro, prohibió, } \\
\text { permitieron, } \\
\text { masacraron, } \\
\text { somos. }\end{array}$ & $\begin{array}{l}\text { Estos verbos conjugados, la mayoría en tiempo pasado y uno en pre- } \\
\text { sente, contienen una carga emotiva, sensible, compasiva y solidaria, } \\
\text { que legitiman un enunciador humano y preocupado por su pueblo } \\
\text { (lloro); pero, a su vez, deslegitiman al presidente Santos que se con- } \\
\text { vierte, con este trino, en un ser cruel e indiferente ante el dolor de su } \\
\text { pueblo, de los soldados y de sus familias. }\end{array}$ \\
\hline
\end{tabular}

Mediante el uso de deícticos temporales contenidos en verbos conjugados, el enunciador se iguala a los soldados, los considera como sus "compañeros", sus pares, indica que él es un soldado más de la patria porque ha pregonado siempre el amor a ella y su defensa a ultranza. Se solidariza públicamente con toda una nación que lloró al unísono la masacre de los soldados. Uribe se "pone en los zapatos" de las familias de los militares y de esta institución, comprende su dolor, rechaza abiertamente las decisiones equivocadas 
del presidente y le reprocha el abandono y la indiferencia frente a quienes exponen su vida diariamente por defender el país. Este trino, que encarna un sollozo, intenta conmover a los seguidores y lectores en general y, con ello, generar inconformismo hacia el presidente.

En suma, mediante el análisis lingüístico de los mensajes de Twitter se develaron sentidos e intencionalidades encaminadas a criticar, denunciar y recriminar las decisiones y actuaciones administrativas y políticas del presidente, para impactar y lograr adhesiones de la opinión pública.

\subsection{Perspectiva sociodiscursiva}

El discurso es social por naturaleza, está cargado de un sinnúmero de sentidos, que además se pueden determinar por indicios u otras voces (explícitas o implícitas) que, a su vez, definen una forma de ver la sociedad y la cultura. El significado de las palabras que se usan en cualquier tipo de discurso, en cualquier mensaje, tiene que ver con el contexto, porque este es básico para entender el sentido de acuerdo con la situación en la que es emitido; un enunciado no tiene un mismo sentido, pues este cambia según el hablante y el contexto en el que se produce. Cualquier análisis del discurso se centra en la opacidad del lenguaje, pues no es transparente, muestra pero también distorsiona y oculta, a veces lo expresado refleja directamente lo pensado y a veces solo es un indicio. La opacidad plantea la relación entre los signos y sus referentes, y establece que la comunicación humana, además de codificar y decodificar, también permite deducir (Grice, 1975; Sperber \& Wilson, 1994); la inferencia posibilita que no solo conozcamos el significado literal de los signos, sino su trasfondo, aquello que se oculta allí, lo que está más allá de la superficie.

Para Van Dijk (2001), el principal propósito del ACD "es hacer visibles o transparentar aquellos aspectos explícitos e implícitos, visibles u opacos, a través de los cuales se reproducen o legitiman relaciones desiguales de poder" (p. 113); por consiguiente, elegir una perspectiva de análisis crítico del discurso conlleva evidenciar los modos como se reproducen o legitiman mecanismos de poder. Según Otaola (1989), el "análisis del discurso ha de ser abordado interdisciplinariamente, aunque exista un predominio de la lingüística" (p. 96); por ello, en este trabajo se analiza el discurso de los tuits desde lo lingüístico, lo sociodiscursivo y lo sociopragmático, lo cual permite desentrañar un cúmulo significativo de múltiples sentidos e intencionalidades que subyacen. El ACD se ha convertido en una herramienta esencial para el estudio de los fenómenos en los que el lenguaje interactúa con aspectos sociales, políticos, culturales, económicos, etc., a través de los medios masivos, contemporáneos, de comunicación. 


\section{Legitimación y deslegitimación}

La legitimación y la deslegitimación son funciones del uso de la lengua y del discurso que involucran un conjunto de estrategias interrelacionadas. Son actos sociales 0 políticos que tienen asidero en los textos o en la conversación (Van Dijk, 1998). La legitimidad se concibe como una cualidad que abarca aristas morales, genuinas, verdaderas y apegadas a la ley (Mendoza-Escalante, 2017). De este concepto se deriva el referente legitimación, como fenómeno sociodiscursivo que le permite a un grupo social (dominante) adquirir consentimiento 0 aprobación por parte de la sociedad (u otros grupos sociales dominados). Por consiguiente, se trata de una manera de persuasión, resignificación y formulación de visiones de mundo que usa un grupo para justificar su ejercicio del poder (Pardo, 2013). Tiene como característica principal la realización en contextos institucionales. En el caso de los mensajes de Twitter analizados aquí, son actores institucionales el presidente del país, su equipo de Gobierno y un expresidente. Ellos cuentan con una investidura especial que, en el ámbito de lo sociopolítico, supone legalidad y poder, dada la posición social que ocupan. Entonces, la legitimación y el poder institucional se amalgaman y de allí surgen discursos legitimadores eminentemente políticos e ideológicos. Por ello, y según Van Dijk (1998), los criterios de pertenencia, las actividades, los objetivos, los recursos (o base del poder), al igual que las normas y valores para cada grupo, no solo regulan y organizan las acciones de sus miembros, sino que también pueden ser utilizadas para justificar sus acciones y su posición social a través de los principios de justicia y de orden moral; y en contraposición, las acciones de los otros grupos son consideradas incorrectas e ilegales, deslegitimadas.

Se debe considerar este hecho particular que se da en las situaciones de legitimación: los grupos dominantes (social, político o económico) no se refieren tan abiertamente a sus propios intereses, sino que recurren a argumentos que presenten sus acciones, 0 políticas, beneficiosas para todos, inclusive para los sectores dominados, al mismo tiempo que ponen en práctica estrategias discursivas para la presentación negativa de los otros (Pérez, 2014). Cuando se emite el discurso para legitimar o deslegitimar, el actor constitucional hace uso de la persuasión y de la manipulación para lograr que se generalice la configuración de una "falsa conciencia". Incluso, estas estrategias discursivas se comparten en un grupo para determinar e incidir en las opiniones y acciones cotidianas de sus miembros y de los sectores dominados (Van Dijk, 1998). No obstante, la hegemonía ideológica no se da de manera total, porque determinados grupos sociales se resisten a dicha manipulación del grupo dominante. 
Por otro lado, fue conveniente conocer el contexto social, histórico y político de los tuits del corpus para interpretarlos, teniendo en cuenta que cada trino alude a una situación y a un ámbito particular de los dos períodos del Gobierno de Juan Manuel Santos abordados en esta investigación. Veamos: cuando en Colombia se crea el partido de la U, su denominación aludía al apellido de Uribe, la U se refería directamente a él, lo cual evidenciaba su influencia en dirigentes políticos regionales, incluso también en el presidente sucesor, Santos; no obstante, al término de su mandato presidencial e inicio de los diálogos de paz comandados por Santos, Uribe abandonó esta corriente política. A pesar de su retiro de la presidencia, el expresidente y senador se ha convertido en una voz fuerte (opositora al Gobierno de Santos), escuchada por muchos, repudiada por otros y vigente en el ámbito político colombiano, pues él aprovecha la televisión, la radio y las redes sociales, en especial su cuenta de Twitter, para pronunciarse cuando está en desacuerdo con las políticas del Gobierno. Algunos colombianos aún ven a Uribe como su salvador, reconocen que su "mano dura" y su política de Seguridad Democrática cambiaron en su momento el destino de la nación. En la época de su mandato, se recuerda siempre la presencia de Uribe en las "zonas rojas" o zonas de conflicto, porque para el pueblo esto reflejaba la imagen de un héroe de la patria, que sin miedo enfrentaba a los actores armados al margen de la ley: guerrillas y grupos paramilitares.

En varias redes sociales (Facebook, Twitter, Instagram, Taringa y YouTube) existen grupos y seguidores que elogian la labor del exmandatario. En una encuesta realizada por History Channel (2013) para elegir al "Gran Colombiano", Uribe logró el 30 \% de los votos y obtuvo esta distinción. Ello demostró que el pueblo había sido impactado por sus discursos, le creían y lo consideraban un personaje relevante en la historia del país.

Siguiendo los postulados de Pardo (2013), en el presente trabajo abordaremos el proceso de legitimación y delegitimación sociodiscursiva a través de las estrategias de persuasión, acusación y justificación en los siete tuits precitados, para evidenciar cómo el enunciador refrenda su poder y desacredita a los enunciatarios: Santos y su equipo de Gobierno. 
Tabla 8. Legitimación y deslegitimación en los tuits de Uribe ${ }^{5}$

\begin{tabular}{|c|c|c|c|}
\hline Tuit & $\begin{array}{c}\text { Fenómeno } \\
\text { sociodiscursivo }\end{array}$ & $\begin{array}{l}\text { Estrategia } \\
\text { discursiva }\end{array}$ & Análisis \\
\hline $\begin{array}{l}\text { 1. "A muchos nos duele la violencia, } \\
\text { otros la aprovechan para su ascenso } \\
\text { político. Ni las tentaciones cómodas } \\
\text { de retiro ni la ofensa diaria nos } \\
\text { apartarán de la batalla alegre y firme } \\
\text { de todas las horas." } \\
\text { (15 abr. 2011) }\end{array}$ & $\begin{array}{l}\text { Legitimación del yo: "a } \\
\text { muchos nos duele la } \\
\text { violencia" } \\
\text { Deslegitimación del } \\
\text { otro: "Otros la apro- } \\
\text { vechan [la violencia] } \\
\text { para su ascenso polí- } \\
\text { tico". }\end{array}$ & $\begin{array}{l}\text { Persuasión } \\
\text { Acusación }\end{array}$ & $\begin{array}{l}\text { Con el uso de un verbo conmovedor } \\
\text { "duele", Uribe manifiesta sentimien- } \\
\text { to y preocupación por el incremento } \\
\text { de actos violentos; de este modo, se } \\
\text { muestra ante la opinión pública como } \\
\text { un expresidente humano, comprome- } \\
\text { tido, sensible, que rechaza la inseguri- } \\
\text { dad y comulga con la legalidad, con el } \\
\text { cumplimiento de la Constitución del } \\
\text { país. } \\
\text { Mediante este enunciado, inculpa, im- } \\
\text { plícitamente, a los grupos armados al } \\
\text { margen de la ley de recurrir al crimen } \\
\text { para mostrar su poderío, impactar en } \\
\text { los contextos nacional e internacional y } \\
\text { posicionarse como una fuerza política } \\
\text { de corte revolucionario. }\end{array}$ \\
\hline $\begin{array}{l}\text { 9. "El Gobierno Santos comunica a } \\
\text { mandos militares que busca nego- } \\
\text { ciar con el terrorismo a través de la } \\
\text { dictadura Chávez, desmotiva a nues- } \\
\text { tros soldados...En nuestro Gobierno } \\
\text { sufrimos terrorismo pero nunca los } \\
\text { cálculos nos llevaron a debilitar la } \\
\text { política". (18 oct. 2012) }\end{array}$ & $\begin{array}{l}\text { Deslegitimación del } \\
\text { otro: "El Gobierno } \\
\text { Santos comunica a } \\
\text { mandos militares que } \\
\text { busca negociar con el } \\
\text { terrorismo a través de } \\
\text { la dictadura Chávez, } \\
\text { desmotiva a nuestros } \\
\text { soldados". } \\
\text { Legitimación del yo: } \\
\text { "En nuestro Gobierno } \\
\text { sufrimos terrorismo } \\
\text { pero nunca los cálcu- } \\
\text { los nos llevaron a de- } \\
\text { bilitar la política". }\end{array}$ & $\begin{array}{l}\text { Acusación } \\
\text { Justificación }\end{array}$ & $\begin{array}{l}\text { Aquí el enunciador invalida un Gobier- } \\
\text { no extranjero, el de Chávez en Vene- } \\
\text { zuela, acusándolo de dictador. Además, } \\
\text { le reprocha al presidente Santos la in- } \\
\text { capacidad para mantener, de manera } \\
\text { soberana, la seguridad del país, pues } \\
\text { con la decisión de pedir ayuda a ese } \\
\text { país, ofende y humilla a los militares } \\
\text { colombianos. } \\
\text { En esta segunda parte del mensaje, } \\
\text { Uribe se favorece a sí mismo, elogia y } \\
\text { valida su Gobierno argumentando que } \\
\text { pese al terrorismo que se vivió en esa } \\
\text { época, no se mermaron las acciones } \\
\text { para contrarrestarlo y mantener la se- } \\
\text { guridad del país. }\end{array}$ \\
\hline
\end{tabular}

5 Este modelo de análisis está basado en los planteamientos metodológicos de Neyla Pardo (2013). 
Tabla 8. Continuación

\begin{tabular}{|c|c|c|c|}
\hline Tuit & $\begin{array}{c}\text { Fenómeno } \\
\text { sociodiscursivo }\end{array}$ & $\begin{array}{l}\text { Estrategia } \\
\text { discursiva }\end{array}$ & Análisis \\
\hline $\begin{array}{l}\text { 12. "Todo lo contrario de aquello que } \\
\text { se decía como Ministro de Defensa y } \\
\text { candidato". } \\
\text { ( } 20 \text { mayo 2012) }\end{array}$ & $\begin{array}{l}\text { Deslegitimación del } \\
\text { otro: "Todo lo contra- } \\
\text { rio de aquello que se } \\
\text { decía como ministro } \\
\text { de Defensa y candida- } \\
\text { to". } \\
\text { Legitimación del yo: } \\
\text { "aquello que se decía" }\end{array}$ & $\begin{array}{l}\text { Acusación } \\
\text { Justificación }\end{array}$ & $\begin{array}{l}\text { Desacredita al enunciatario endilgán- } \\
\text { dole una doble moral: el enunciador } \\
\text { le recuerda a Santos que como su mi- } \\
\text { nistro de Defensa y como candidato a } \\
\text { la presidencia expresó una ideología } \\
\text { similar a la suya (Uribe), pero como } \\
\text { presidente, actúa de modo adverso. } \\
\text { Implícitamente lo acusa de incon- } \\
\text { gruente y desleal. } \\
\text { De manera implícita, el enunciador } \\
\text { defiende y acredita sus acciones guber- } \\
\text { namentales del pasado, al insinuar que } \\
\text { Santos como su ministro de Defensa y } \\
\text { luego como candidato a la presidencia, } \\
\text { coincidía con las posturas de su jefe } \\
\text { (Uribe), es decir, hacía lo "correcto". }\end{array}$ \\
\hline $\begin{array}{l}\text { 16. "Sorpresas: antes fuimos útiles } \\
\text { en TLC con USA, ahora lo hizo la ha- } \\
\text { bilidad del Gbno (sic) actual" } \\
\text { (12 abr. 2012) }\end{array}$ & $\begin{array}{l}\text { Legitimación del yo: } \\
\text { "Sorpresas: antes fui- } \\
\text { mos útiles en TLC con } \\
\text { USA" } \\
\text { Deslegitimación del } \\
\text { otro: "ahora lo hizo } \\
\text { la habilidad del Gbno } \\
\text { (sic) actual" }\end{array}$ & $\begin{array}{l}\text { Justificación } \\
\text { Acusación }\end{array}$ & $\begin{array}{l}\text { El expresidente acredita su gestión ad- } \\
\text { ministrativa recordándoles a los enun- } \\
\text { ciatarios y a la opinión pública que el } \\
\text { TLC (Tratado de Libre Comercio) con } \\
\text { Estados Unidos se logró gracias tam- } \\
\text { bién al trabajo adelantado durante su } \\
\text { Gobierno. } \\
\text { Uribe denuncia la desfachatez de San- } \\
\text { tos al atribuirse el logro del TLC con } \\
\text { Estados Unidos, desconociendo por } \\
\text { completo la gestión realizada por el } \\
\text { Gobierno anterior. }\end{array}$ \\
\hline $\begin{array}{l}\text { 20. "Pte (sic) Santos miente, jamás } \\
\text { le recomendé un ministro". ( } 9 \text { febr. } \\
\text { 2013) }\end{array}$ & $\begin{array}{l}\text { Deslegitimación del } \\
\text { otro: "Pte (sic) Santos } \\
\text { miente" } \\
\text { Legitimación del yo: } \\
\text { "jamás le recomendé } \\
\text { un ministro". }\end{array}$ & $\begin{array}{l}\text { Acusación } \\
\text { Justificación }\end{array}$ & $\begin{array}{l}\text { Este trino contiene una información } \\
\text { implícita: previamente Santos había } \\
\text { argumentado ante los medios que el } \\
\text { inconformismo de Uribe se debía a que } \\
\text { no le había nombrado como ministro } \\
\text { a un amigo. En respuesta a ese co- } \\
\text { mentario, el expresidente publica este } \\
\text { mensaje en el que se defiende desacre- } \\
\text { ditando al presidente con el calificativo } \\
\text { mentiroso. } \\
\text { Cuando Uribe niega terminantemente } \\
\text { con el adverbio "jamás", se defiende } \\
\text { para mantener en alto su imagen de } \\
\text { político ético y expresidente probo. }\end{array}$ \\
\hline
\end{tabular}


Tabla 8. Continuación

\begin{tabular}{|c|c|c|c|}
\hline Tuit & $\begin{array}{c}\text { Fenómeno } \\
\text { sociodiscursivo }\end{array}$ & $\begin{array}{l}\text { Estrategia } \\
\text { discursiva }\end{array}$ & Análisis \\
\hline $\begin{array}{l}\text { 22. "Señor presidente Santos, la trai- } \\
\text { ción a la Patria es uno de los delitos } \\
\text { en que está incurriendo su Gobierno } \\
\text { porque permite que asesine a los } \\
\text { soldados y a policías y le da impu- } \\
\text { nidad. Eso es traición a la patria". (9 } \\
\text { abr. 2013) }\end{array}$ & $\begin{array}{l}\text { Deslegitimación del } \\
\text { otro: 'Señor presiden- } \\
\text { te Santos, la traición a } \\
\text { la Patria es uno de los } \\
\text { delitos en que está in- } \\
\text { curriendo su Gobierno } \\
\text { porque permite que } \\
\text { asesine a los soldados } \\
\text { y a policías y le da im- } \\
\text { punidad'. }\end{array}$ & Acusación & $\begin{array}{l}\text { Uribe descalifica e invalida el actuar del } \\
\text { presidente y su equipo de Gobierno al } \\
\text { responsabilizarlos del no castigo de los } \\
\text { crímenes cometidos por los grupos ile- } \\
\text { gales alzados en armas. }\end{array}$ \\
\hline $\begin{array}{l}\text { 24. "Lloro por mis compañeros ase- } \\
\text { sinados, por el desengaño de saber } \\
\text { que el presidente Santos prohibió el } \\
\text { bombardeo a los señores de las Farc } \\
\text { permitieron que los masacraran vil- } \\
\text { mente, porque para él somos sim- } \\
\text { plemente unos desechables". } \\
(20 \text { abr. } 2015)\end{array}$ & $\begin{array}{l}\text { Deslegitimación del } \\
\text { otro: "el presidente } \\
\text { Santos prohibió el } \\
\text { bombardeo a los se- } \\
\text { nores de las FARC per- } \\
\text { mitieron (sic) que los } \\
\text { masacraran vilmente, } \\
\text { porque para él somos } \\
\text { simplemente unos } \\
\text { desechables." } \\
\text { Legitimación del yo: } \\
\text { "Lloro por mis com- } \\
\text { pañeros asesinados, } \\
\text { por el desengaño" }\end{array}$ & $\begin{array}{l}\text { Acusación } \\
\text { Persuasión }\end{array}$ & $\begin{array}{l}\text { Se repudia con ira y dolor una decisión } \\
\text { tomada por el presidente, se le señala } \\
\text { como el culpable de la muerte de unos } \\
\text { soldados, delito perpetrado por la gue- } \\
\text { rrilla de las FARC, paradójicamente, en } \\
\text { el marco de un desescalamiento del } \\
\text { conflicto. } \\
\text { El enunciador enaltece su imagen al } \\
\text { expresar emotivamente su nostalgia } \\
\text { por la muerte de los soldados, a quie- } \\
\text { nes, póstumamente, les manifiesta } \\
\text { afecto y consideración. Todo el mensa- } \\
\text { je se convierte en una estrategia argu- } \\
\text { mentativa para conmover a los colom- } \\
\text { bianos e intentar convencerlos de la no } \\
\text { conveniencia de la negociación de un } \\
\text { proceso de paz con las FARC, porque, } \\
\text { según él, siempre incumplen lo que } \\
\text { pactan con el Gobierno. }\end{array}$ \\
\hline
\end{tabular}

En síntesis, este análisis sociodiscursivo dejó ver que a través de los tuits, el expresidente Uribe permanentemente está legitimando sus principios político-ideológicos y sus actuaciones pasadas y presentes a costa de la deslegitimación de su sucesor y el grupo de colaboradores, pues la intención es mostrar que su Gobierno fue mejor que el actual y, sobre todo, que aún tiene poder.

\subsection{Perspectiva sociopragmática}

La sociopragmática se encarga de estudiar el lenguaje en contexto, esto es, los fenómenos que se dan cuando se producen los actos de habla en sus diferentes situaciones comunicativas. En este apartado se analiza una muestra del corpus con apoyo en el modelo comunicativo de Grice (1975) para los estudios pragmáticos. Esta teoría comunicativa, 
conocida como inferencial, determina que el emisor y el receptor codifican y decodifican mensajes, pero el acto de comunicar va más allá, puesto que este es muy complejo; en el proceso de comunicación hay malentendidos, ambigüedades, implicaturas, ironías, que suceden y se entienden dentro de un ámbito específico. Aquí se retoma para el análisis el concepto de implicatura, entendido como la distinción entre lo que se dice y lo que se comunica, es decir, entre el significado convencional de las palabras que conforman un determinado enunciado y el sentido que estas mismas implican. Lo que se dice es el contenido literal, explícito, expresado en el enunciado, y lo que se comunica es el contenido implícito, oculto; lo que no se dice, pero se da a entender, lo que va más allá del contenido proposicional explícito, lo que subyace.

Este fenómeno sociopragmático se refiere a las informaciones implícitas que se pueden evidenciar mediante dos formas, cuando se trata de las convencionales, que derivan directamente de las palabras, y las no convencionales o llamadas también conversacionales, que son las que se generan por la intervención de principios conversacionales, ya sea que se utilicen o se violen las máximas de cooperación, cantidad, calidad, entre otras. En este trabajo se abordarán las denominadas implicaturas conversacionales particularizadas, aquellas que dependen de un contexto o situación específica de emisión. En los mensajes de Twitter seleccionados y analizados en la Tabla 9, se puede evidenciar las situaciones comunicativas que implícitamente subyacen al mensaje literal. Por ello, en dicha tabla se registran los siguientes elementos: descripción del tuit (mensaje), contexto situacional: descripción de la realidad sociopolítica y sentido de las implicaturas particularizadas. Para este tipo de análisis se eligieron los siguientes tuits, puesto que su discurso es más opaco, no tan explícito como el de otros que también hacen parte del corpus: 4, 7, 8, 10. 11, 25 y 28.

Tabla 9. Contexto situacional e implicaturas particularizadas.

\begin{tabular}{|l|l|l|}
\hline \multicolumn{1}{|c|}{ Tuit } & $\begin{array}{c}\text { Contexto } \\
\text { situacional: } \\
\text { descripción } \\
\text { de la realidad } \\
\text { sociopolítica }\end{array}$ & \multicolumn{1}{|c|}{ Sentido de las implicaturas particularizadas } \\
\hline $\begin{array}{l}\text { 4. "Este gobierno no } \\
\text { necesita graduarnos } \\
\text { de corruptos, para } \\
\text { adelantar su política } \\
\text { contra la corrupción" } \\
\text { (13 jun. 2011) }\end{array}$ & $\begin{array}{l}\text { Implementación } \\
\text { de políticas } \\
\text { anticorrupción del } \\
\text { presidente Santos }\end{array}$ & $\begin{array}{l}\text { Para comprender el contexto situacional en el que es emitido este } \\
\text { tuit, es necesario informar que uno de los programas bandera del } \\
\text { presidente Santos fue el de contrarrestar la corrupción. Cuando Uribe } \\
\text { señala que Santos no necesita acusar al Gobierno anterior de corrupto } \\
\text { para implementar políticas anticorrupción, da a entender que es el } \\
\text { actual Gobierno el que está incurriendo en ella, a través del derroche } \\
\text { financiero en campañas publicitarias que aparecen en todos los } \\
\text { medios de comunicación del país. }\end{array}$ \\
\hline
\end{tabular}


Tabla 9. Continuación

\begin{tabular}{|c|c|c|}
\hline Tuit & $\begin{array}{l}\text { Contexto } \\
\text { situacional: } \\
\text { descripción } \\
\text { de la realidad } \\
\text { sociopolítica }\end{array}$ & Sentido de las implicaturas particularizadas \\
\hline $\begin{array}{l}\text { 7. "Preocupa que el } \\
\text { esfuerzo por Colombia } \\
\text { quede así, que en lugar } \\
\text { de redistribución haya } \\
\text { despojo: Con Santos se } \\
\text { fue la prosperidad, el } \\
\text { raponazo a las regalías } \\
\text { dejó al Meta sin inver- } \\
\text { sión". } \\
(20 \text { mayo 2013) }\end{array}$ & $\begin{array}{l}\text { Distribución de los } \\
\text { ingresos del Estado }\end{array}$ & $\begin{array}{l}\text { Uribe indica, implícitamente, que en su época de gobernante a ningún } \\
\text { departamento se le quitaron sus ingresos por concepto de regalías, } \\
\text { siempre se procuró que contaran con ellos para invertir, para generar } \\
\text { progreso. Pero Santos, sin ningún reparo, interviene y priva de esos } \\
\text { dineros a algunas comunidades en detrimento de su desarrollo } \\
\text { y calidad de vida, lo que se convierte en una contradicción de su } \\
\text { propio lema de campaña "Prosperidad para todos". En este mensaje, } \\
\text { Uribe aprovecha para recordarle a la opinión pública los logros de su } \\
\text { mandato, en materia de asignación de recursos económicos, con lo } \\
\text { cual exalta nuevamente su imagen. }\end{array}$ \\
\hline $\begin{array}{l}\text { 8."El actual gobierno } \\
\text { de Colombia, en lugar } \\
\text { de combatir al terroris- } \\
\text { mo, busca mediación } \\
\text { de Venezuela" } \\
(22 \text { mayo 2012) }\end{array}$ & $\begin{array}{l}\text { Relaciones } \\
\text { diplomáticas del } \\
\text { Gobierno de Santos } \\
\text { con Venezuela }\end{array}$ & $\begin{array}{l}\text { El mensaje implícito aquí es denunciar la equivocación de Santos } \\
\text { al solicitar ayuda del país vecino para negociar un proceso de paz } \\
\text { con las FARC, pues, en el criterio de Uribe, la mejor solución es el } \\
\text { sometimiento de este grupo armado al margen de la ley por la vía } \\
\text { militar, sin acudir a un país, que según él, ha sido su auxiliador. }\end{array}$ \\
\hline $\begin{array}{l}\text { 10. "Qué peligro, qué } \\
\text { vanidad de poder igno- } \\
\text { re violencia contra el } \\
\text { pueblo y acuda a Cuba } \\
\text { a complacer al terro- } \\
\text { rismo. Pte. Santos en } \\
\text { Cuba con Márquez". } \\
\text { (18 oct. 2012) }\end{array}$ & $\begin{array}{l}\text { Proceso de paz: } \\
\text { diálogos en La } \\
\text { Habana, Cuba }\end{array}$ & $\begin{array}{l}\text { De este trino se infiere el rechazo absoluto a cualquier acercamiento } \\
\text { del presidente con integrantes de las FARC. Uribe repudia también } \\
\text { la solicitud de ayuda a Cuba para dialogar con esta guerrilla, dado } \\
\text { que, según el expresidente, este es un país que también ha apoyado y } \\
\text { patrocinado desde su origen a este grupo revolucionario. }\end{array}$ \\
\hline $\begin{array}{l}\text { 11. "Necesitamos un } \\
\text { gobierno más efectivo } \\
\text { y menos vanidoso me- } \\
\text { nos manipulador" } \\
(10 \text { mayo 2012) }\end{array}$ & $\begin{array}{l}\text { Ineficacia de } \\
\text { las políticas } \\
\text { económicas, sociales } \\
\text { y de seguridad } \\
\text { implementadas } \\
\text { por el Gobierno de } \\
\text { Santos }\end{array}$ & $\begin{array}{l}\text { Este tuit contiene implícitamente la petición de renuncia del presidente } \\
\text { Santos; la justificación está dada a través adjetivos descalificativos: } \\
\text { ineficaz, "vanidoso" y "manipulador". } \\
\text { Para Uribe, Santos ha centrado su Gobierno en una imagen falsa del } \\
\text { típico "paraíso" y la falacia de un acuerdo de paz, cuando la realidad } \\
\text { es que en el país no cesa la violencia y reina el caos. Seguramente, } \\
\text { algunos lectores de este mensaje comprenderán y reconocerán que } \\
\text { el Gobierno de Santos es incompetente para brindar a los ciudadanos } \\
\text { bienestar social, seguridad y tranquilidad. }\end{array}$ \\
\hline
\end{tabular}


Tabla 9. Continuación

\begin{tabular}{|l|l|l|}
\hline \multicolumn{1}{|c|}{ Tuit } & \multicolumn{1}{|c|}{$\begin{array}{c}\text { Contexto } \\
\text { situacional: } \\
\text { descripción } \\
\text { de la realidad } \\
\text { sociopolítica }\end{array}$} & \multicolumn{1}{c|}{ Sentido de las implicaturas particularizadas } \\
\hline $\begin{array}{l}\text { 25."Menos grave que } \\
\text { Santos incumpla la re- } \\
\text { frendación a que enga- } \\
\text { ñe con el Plebiscito". } \\
\text { (10 nov. 2015) }\end{array}$ & $\begin{array}{l}\text { Propuesta de Santos } \\
\text { de un plebiscito para } \\
\text { que el pueblo avale } \\
\text { los Acuerdos de paz }\end{array}$ & $\begin{array}{l}\text { De este mensaje se infiere que Uribe pronostica el desconocimiento, } \\
\text { por parte de Santos, de un resultado del plebiscito adverso para sus } \\
\text { propósitos. Se lee entre líneas que el expresidente desconfía de las } \\
\text { actuaciones de Santos en lo relacionado con el proceso de paz con } \\
\text { las FARC. }\end{array}$ \\
\hline $\begin{array}{l}\text { 26."La apropiación } \\
\text { personal de la cheque- } \\
\text { ra del Estado por parte } \\
\text { de Santos es otra expre- } \\
\text { sión del imperio contra } \\
\text { institucional". } \\
\text { (14 nov. 2015) }\end{array}$ & $\begin{array}{l}\text { Manejo inapropiado } \\
\text { del presupuesto de la }\end{array}$ & $\begin{array}{l}\text { La implicatura aquí está dada en una acusación grave: el hurto y la } \\
\text { corrupción en el manejo del erario público por parte del presidente } \\
\text { Santos. Además del hurto, implica que hay otras acciones de Santos y } \\
\text { su Gobierno que van en contravía de la institucionalidad del país. Uri- } \\
\text { be muestra una autoimagen positiva y poderosa, pues se erige como } \\
\text { vigía del manejo y de la transparencia en la administración del Estado. }\end{array}$ \\
\hline
\end{tabular}

Sintetizando, al desentrañar algunas implicaturas particularizadas contenidas en el discurso de siete mensajes de Twitter, se evidenció cómo el expresidente Uribe ejerce su poder para influir en sus lectores-enunciatarios y en la opinión pública, en general.

\section{Conclusiones}

En los tuits enviados por Uribe al presidente Santos y su equipo de Gobierno se observa el uso recurrente de deícticos de persona, de tiempo y de espacio para expresar su inconformismo con la forma como el presidente gobierna a Colombia. Concretamente, critica, denuncia y le recrimina las decisiones y las actuaciones administrativas y políticas, así: lamenta el incremento de la violencia, interpreta el sentimiento y el repudio generalizado hacia los actos criminales perpetrados por los grupos armados al margen de la ley, muestra cercanía con el pueblo, toca sus fibras más sensibles para generar reacciones en contra del Gobierno de Santos, ataca la imagen del presidente delatando sus equivocaciones y su deshonestidad al atribuirse logros que no le corresponden, intenta crear conciencia en la opinión pública sobre el rumbo inapropiado que toma el país, le reprocha al presidente el desestímulo y la desprotección de los militares, lo califica de mentiroso, lo acusa de traidor a la patria por permitir que los grupos ilegales alzados en armas atenten contra las Fuerzas Armadas. En cambio, les recuerda a los enunciatarios (presidente Santos, equipo de Gobierno y lectores en general) los aciertos de su mandato y deplora la abolición de su política de Seguridad Democrática. Así que, a través del análisis lingüístico 
de los mensajes de Twitter se logró revelar múltiples sentidos que subyacen al uso de deícticos, especialmente, la intención del enunciador de reproducir un poder que le posibilite incidir en la opinión pública en cuanto a modos de pensar, de sentir, de percibir la realidad política del país y la forma como se está gobernando.

Ahora, Uribe legitima su yo mediante la persuasión, pues con el empleo de verbos emotivos como "duele" conmueve a la opinión pública para ganar y mantener su afecto, su comprensión, su beneplácito y, finalmente, su adhesión. Pero, al mismo tiempo, implícitamente deslegitima a la guerrilla de las FARC, les repudia el hecho de recurrir al crimen para conseguir poder, impactar en los contextos nacional e internacional y posicionarse como una fuerza política de corte revolucionario. Deslegitima también a Santos cuando le critica su decisión de solicitar la ayuda del presidente de Venezuela Hugo Chávez para iniciar el proceso de paz con la guerrilla de las FARC, argumentando que este presidente extranjero ha sido auxiliador de dicho grupo insurgente; le reprocha a Santos la incapacidad para mantener, de manera soberana, la seguridad del país, dado que con sus decisiones ofende y humilla a los militares colombianos. Consecuentemente, Uribe se legitima al justificar su buen Gobierno aduciendo que nunca mermó las acciones para contrarrestar el terrorismo y mantener la seguridad del país. Nuevamente deslegitima la imagen de Santos al denunciar su desfachatez y deshonestidad al atribuirse la firma del TLC con Estados Unidos, sin reconocer las gestiones y el trabajo adelantado por el Gobierno antecesor.

En suma, este análisis sociodiscursivo reveló que mediante el discurso de los tuits, Uribe constantemente está legitimando sus acciones y sus principios políticos e ideológicos a costa de la deslegitimación de su sucesor y el grupo de colaboradores, pues es clara la intención de mostrar que su Gobierno fue mejor que el actual y que, por ello, aún ejerce poder en la opinión pública.

Mediante el análisis de las implicaturas de los tuits analizados se halló lo siguiente: en respuesta a la acusación de corrupción que lanza Santos al Gobierno anterior (tuit 4), Uribe le censura las políticas propuestas para frenarla, pues no entiende por qué se apoya en acusaciones falsas al antecesor y a su equipo de colaboradores y no en acciones concretas y eficaces; a su vez, critica el derroche de los recursos económicos del Estado. En el tuit 7 Uribe aduce, implícitamente, que en su época de gobernante a ningún departamento se le retiraron sus ingresos por concepto de regalías, siempre se procuró que contaran con ellas para generar progreso; en cambio, Santos despojó de sus regalías al departamento del Meta, dejándolo sin posibilidades de inversión y de mejora de la calidad de vida de esa comunidad, lo que, paradójicamente, contradice su programa bandera "Prosperidad para todos". En el tuit 11 ("Necesitamos un gobierno más efectivo y menos vanidoso menos 
manipulador", 10 mayo 2012), tácitamente Uribe pide la renuncia del presidente Santos, pues lo califica de "vanidoso", "manipulador" e ineficaz. Con este mensaje, seguramente algunos lectores comprenderán y se convencerán de que Santos es incompetente para dirigir la nación.

Del tuit 25 se infiere el pronóstico del desconocimiento por parte de Santos del resultado adverso del plebiscito. En el tuit 26, la implicatura corresponde a una acusación al presidente Santos de hurto y corrupción en el manejo de los dineros públicos. También se puede colegir de este mensaje, que Uribe se propone mostrar una autoimagen positiva, por cuanto destaca su responsabilidad y transparencia en la administración del presupuesto del Estado. Con este análisis sociopragmático salieron a la luz implicaturas que muestran las diferentes maneras como el enunciador ejerce el poder para inmiscuirse crítica y públicamente en los acontecimientos políticos, sociales y económicos de la vida nacional y, a la vez, incidir y ganar aceptación en la opinión pública.

Y en último término, a través de los 27 tuits analizados, el enunciador establece comparaciones entre los dos gobiernos, muestra a la opinión pública lo positivo de él como gobernante, y lo negativo de Santos en ese mismo rol. Consideramos que la aceptación de esos mensajes por parte de sus seguidores tiene que ver con la fuerza de los argumentos, que son expuestos en el momento preciso y con un lenguaje sencillo, directo, franco y asequible a cualquier colombiano, aunque en algunos casos, tan irónico y agresivo, que raya en el abuso, lo cual surge de su propia convicción de poder.

\section{Referencias}

Arrieta, L.M. (2013). La construcción de los sujetos en el discurso del expresidente Uribe Vélez: un análisis desde las tonalidades valorativas y los actos de habla. Cuadernos de Lingüistica Hispánica, (21), 103-116.

Grice, H. P. (1975). Lógica y conversación. En L. Valdés, La búsqueda del significado (pp. 511530). Madrid: Tecnos/Universidad de Murcia.

Jakobson, R. (1957). Los conmutadores, las categorías verbales y el verbo ruso. J. Bauzá \& M. J. Muñoz (trads.). Recuperado de http://88.27.249.81/psico/sesion/ficheros_publico/ descargaficheros.php?opcion $=$ textos\&codig $0=50$

Lyons, J. (1980). Sémantique linguistique. París: Larousse.

Mendoza-Escalante, A. (2017). La dicotomía guerra/paz en los videos de la campaña de reelección presidencial de Juan Manuel Santos (Colombia). Análisis de las estrategias de legitimación. Cuadernos de Lingüística Hispánica, (29), 107-125. 
Noguera, S. (2010). Estudio y ejercitación de la enunciación, la textualidad, la explicación y la argumentación. Buenos Aires: Biblos.

Otaola, C. (1989). El análisis del discurso. Introducción teórica. Epos Revista de Filología, (5), 81-97. Recuperado de http://revistas.uned.es/index.php/EPOS/article/viewFile/96 56/9202

Pano, A. \& Mancera, A. (2014). La "conversación" en Twitter: las unidades discursivas y el uso de marcadores interactivos en los intercambios con parlamentarios españoles en esta red social. Estudios de Lingüística del Español, 35, 234-268. Recuperado de http://www.raco. cat/index.php/Elies/article/view/285730/373701

Pardo, N. (2013). Cómo bacer análisis crítico del discurso. Una perspectiva latinoamericana. Bogotá: Universidad Nacional de Colombia, IECO.

Pérez, V. (2014). Identidad individual y grupal en Twitter. Discurso \& Sociedad, 8(3), 482- 506.

Sperber, D. \& Wilson, D. (1986). Relevance: Communication and Cognition. (2 ${ }^{\text {nd }}$ ed.). Estados Unidos: Wiley-Blackwell.

Van Dijk, T. (1995). Análisis del discurso ideológico. En E. Ventola \& A. Solin (eds.), Special issue Interdisciplinary approaches to Discourse Analysis (pp. 135-161). New Courant: University of Helsinki.

Van Dijk, T. (1998). Ideología, una aproximación multidisciplinaria. Barcelona: Gedisa.

Van Dijk, T. (2001). Discurso, ideología y contexto. Folio Lingüístico, 35(1-2), 11-40.

Van Dijk, T. (2009). Discurso y poder. Barcelona: Gedisa.

Verón, E. (1985). El análisis del contrato de lectura, un nuevo método para los estudios de posicionamiento de los soportes de los media. En Les medias: experiences, recherches actuelles, aplications. Paris: Irep. 